http://dx.doi.org/10.18675/1981-8106.vol25.n48.p19-36

\title{
A influência das representações sociais na construção da identidade profissional docente
}

\section{The influence of social representations in the construction of teacher professional identity}

\section{La influencia de las representaciones sociales en la construcción de la identidad profesional docente}

\author{
Andrea Velloso' \\ Denise Lannes" \\ 'Universidade do Grande Rio (UNIGRANRIO), Rio de Janeiro - Brasil. E-mail: \\ andrea.velloso@unigranrio.com.br \\ " Universidade Federal do Rio de Janeiro (UFRJ), Rio de Janeiro - Brasil. E-mail: \\ lannes@bioqmed.ufrj.br
}

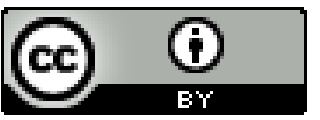

Educação: teoria e prática, Rio Claro, SP, Brasil - eISSN: 1981-8106

Está licenciada sob Licença Creative Common

\section{Resumo}

Trata-se de um estudo sobre a constituição da identidade docente, considerando as dimensões individuais e grupais, como possível revelador das singularidades dos professores sobre suas identidades pessoais e coletivas. Apresentamos um estudo de caso do Instituto de Bioquímica Médica da UFRJ, onde se pretende identificar as Representações Sociais (RS) de professores (Educação Básica e Superior) e sua influência na construção da identidade profissional dos mesmos, a partir da relação entre a organização da RS, a análise de coocorrência das palavras evocadas e a análise hierárquica de agrupamentos das palavras em grupos homogêneos (Clusters). Participaram 115 docentes no total. No contexto observado, parece haver uma polarização das representações de professor, entre os docentes dos diferentes níveis de ensino, resultante do desequilíbrio entre identidade docente. Posicionam os professores do Ensino Superior e da Educação Básica, em polos opostos e irreconhecíveis acarretando as muitas barreiras de comunicação verificadas entre eles. Discute-se, aqui, a implicação da identidade 
profissional assumida com circunstância institucional que impõe os tipos de relações e ações capazes de vencer os obstáculos enfrentados na prática docente.

Palavras-chave: Identidade Profissional; Representações Sociais; Professor.

\begin{abstract}
This study of how teachers' personal and collective identities are constructed was undertaken with a view to delineating the uniqueness of different groups of teachers and defining the professional and social significance of being a teacher. This study aims to identify the social representations about teacher and its influence on the construction of professional identity, in a case study from the Institute of Medical Biochemistry, UFRJ. A total of 115 teachers (Higher Education and Basic Education) participated. In the context observed, there seems to be a polarization of representations of teacher among teachers of different grade levels. Position teachers of Higher Education and Basic Education, and unrecognizable on opposite poles causing the many communication barriers between them verified. We discuss here the professional implication of assumed identity with institutional circumstance that requires the kinds of relationships and actions that can overcome the obstacles faced in teaching practice.
\end{abstract}

Keywords: Professional Identity; Social Representations; Teacher.

\title{
Resumen
}

Se trata de un estudio sobre la constitución de la identidad docente, considerando las dimensiones individuales y grupales, como posible revelador de las singularidades de los profesores sobre sus identidades personales y colectivas. Presentamos un estudio de caso del Instituto de Bioquímica Médica de la UFRJ (Universidad Federal de Rio de Janeiro), donde se pretende identificar las Representaciones Sociales (RS) de profesores (Educación Básica y Superior) y su influencia en la construcción de la identidad profesional de los mismos, a partir de la relación entre la organización de las $R S$, el análisis de ocurrencia de las palabras evocadas y el análisis jerárquico de agrupamientos de palabras en grupos homogéneos (Clusters). Participaron 115 docentes en total. En el contexto observado, parece haber una polarización de las representaciones de profesor, entre los docentes de los diferentes niveles de enseñanza, resultante del desequilibrio entre identidad docente. Posicionan a los profesores de la Enseñanza Superior y de la Educación Básica, en polos opuestos e irreconocibles acarreando las muchas barreras de comunicación verificadas entre ellos. Se discute, aquí, la implicación de la identidad profesional asumida con circunstancia institucional, que impone los tipos de relaciones y acciones capaces de vencer los obstáculos enfrentados en la práctica docente.

Palabras clave: Identidad Profesional; Representaciones Sociales; Profesor. 


\section{Introdução}

A maior parte das investigações que problematizam a identidade e a profissionalização docente busca aspectos unificadores e fundantes da identidade profissional dessa categoria, ora circunscritos à formação profissional, ora à natureza do processo de trabalho, à história de vida ou, mesmo, às questões de gênero (CARBONE; MENIN, 2004; SHIMAMOTO; LIMA, 2006).

Talvez um caminho mais adequado para a pesquisa nessa área seja buscar as diferenças, as descontinuidades e as divisões dessa categoria, privilegiando as narrativas dos professores acerca de si mesmos e de seus contextos de trabalho. $\mathrm{O}$ objetivo não seria o de reificarmos seus próprios pontos de vista ou tomá-los como a medida mais justa do que de fato acontece, mas, a partir do que os divide, professores universitários e professores da Educação Básica no Brasil, por exemplo, talvez, pudéssemos nos aproximar da dinâmica contraditória e fragmentada em que estão mergulhados. A começar por sua constituição como grupo social.

Uma discussão que nos parece bastante interessante e relevante envolve o fato da identidade profissional docente ser construída de forma muito peculiar, diferente de qualquer outra identidade profissional, uma vez que admite a socialização primária como referencial constitutivo. Isto porque, os grupos formados por mestres e aprendizes, de uma forma ou de outra, existem em todas as sociedades; são universais; portanto, primários segundo a definição de Cooley (1962). Provavelmente tanto quanto os membros familiares, os professores que cuidam da educação básica conformam nossas individualidades, estando impregnados no referencial mais basal de nossas identidades. Fomos, todos, professorados. Com algumas exceções, sabemos bem sobre o fazer e o ser professor, tanto quanto sabemos sobre o fazer e o ser mãe ou pai, irmã ou irmão, avó ou avô. Os professores povoam nossas memórias da mesma forma que os amigos e as brincadeiras de infância.

Sob esta perspectiva, quais seriam, então, as referências e representações que delineiam a identidade docente? Elas emergem das experiências e modelos individuais, caracterizando-a, de forma singular, como somatório de individualidades em um todo comum? Ou fundamentam-se em um arquétipo de professor constituído como produto histórico-social?

\subsection{Identidade Profissional e Representações Sociais}

O conhecimento das representações sociais dos docentes, como um conjunto organizado de julgamentos e informações elaborados a respeito do que é ser professor, parece ser um caminho promissor para revelar como funcionam os sistemas de referência que identificam pessoas e grupos e determinam suas atitudes. O pressuposto de Moscovici (2003, p.40) de que "todas as interações humanas pressupõem representações, sejam elas entre duas pessoas ou entre grupos sociais", estimulou os estudos de Abric, propondo que a base da identidade de um determinado grupo está diretamente relacionada às representações que 
compartilham. Nesse contexto, as representações sociais são construídas a partir de formas específicas de comportamento e comunicação, com a construção de consensos ancorados nos repertórios culturais e históricos próprios do grupo, ou seja, constroem a realidade. As RS definem tanto o estímulo quanto a resposta que evocam. Não se configura como simples orientação para o comportamento, ela refaz modelos e ressignifica as informações do ambiente em que o comportamento se sucederá. "Novos códigos para nomear e classificar os vários aspectos do cotidiano são providenciados" (FLATH; MOSCOVICI, 1983,p.123-124).

Considera-se que a estrutura de uma Representação Social é alterada quando são adicionados ou suprimidos elementos do seu Núcleo Central. Tais mudanças costumam ser pouco frequentes e, geralmente, estão restritas à ocorrência de eventos muito significativos, que levem o sujeito a rever seus valores, expectativas e conceitos de forma radical.

As RS permitem uma explicação e compreensão da realidade, definindo sua identidade, guiando os comportamentos e as práticas de seus integrantes, assim como, justificando as tomadas de posição, ou seja, dando sentido às condutas dos indivíduos.

O estudo de caso único - o do Instituto de Bioquímica Médica (IBqM) da Universidade Federal do Rio de Janeiro (UFRJ) - foi a estratégia de pesquisa escolhida para conhecermos os sistemas de referência constitutivos das identidades docentes, a partir da análise das Representações Sociais de grupos distintos de professores que constituem este Instituto de Pesquisa, acerca do que é ser professor. O estudo de caso foi escolhido, pois além de caracterizar-se como uma investigação empírica de um fenômeno contemporâneo, que não pode ser desvinculado de seu contexto real e amplo, apresentava dois grupos distintos de professores (Educação Superior e Educação Básica), interagindo em um mesmo ambiente.

Assim, foram escolhidos como sujeitos desta pesquisa representantes de dois grupos sociais de professores vinculados ao Instituto de Bioquímica Médica (IBqM) da Universidade Federal do Rio de Janeiro (UFRJ), totalizando um universo amostral de 115 sujeitos. Um grupo é constituído por 41 professores da Educação Superior, sendo 27 homens e 14 mulheres. Todos são membros do corpo docente do IBqM, em sua maioria Bacharéis em Ciências Biológicas, com idade média de 42,4 anos. Os sujeitos desse grupo exercem a profissão docente há pelo menos 16 anos e dedicam, aproximadamente, 44 horas semanais à atividade docente na graduação, tendo como atividade principal a pesquisa científica na área básica. O segundo grupo é formado por 74 professores da Educação Básica - matriculados no curso de Pós-Graduação lato sensu - Especialização em Ensino de Ciências e Biologia do Instituto. São 17 homens e 57 mulheres, com idade média de 33,7 anos, que exercem a profissão há sete anos, em média, tendo, todos, cursado na graduação a modalidade formação de professores (licenciatura). A maioria desses professores leciona as disciplinas de Ciências e/ou Biologia, em escolas das redes pública e particular, da região metropolitana do Rio de Janeiro.

Solicitamos, então, aos 115 participantes, que listassem as oito primeiras palavras que lhes viessem à mente, relacionadas ao termo indutor professor. A técnica da associação livre de palavras permite a evidência de universos semânticos de palavras que agrupam 
determinadas populações, expressando os valores que, em geral, o sujeito não tem consciência ou não explicita, mas que direcionam a sua ação e definem seu comportamento (ABRIC, 1998; COUTINHO; SALDANHA, 2005).

\subsection{Identificação do Núcleo Central}

Os elementos do Núcleo Central representam a essência da Representação Social, o que é inegociável, constituído, portanto, dos elementos mais estáveis e resistentes à mudança (ABRIC, 2003). Para a identificação dos elementos do NC levamos em conta as três características que permitem diferenciá-los dos outros elementos da representação social, são elas: a saliência, o poder associativo e o poder simbólico.

A saliência se refere ao fato das cognições centrais ocuparem um lugar privilegiado na representação, sendo evocadas com maior frequência e prioridade que as demais (MOLINER, 1994). Esses critérios lexicográficos permitem uma aproximação da noção de prototipicidade dos elementos de uma representação, a partir da compreensão das distâncias estabelecidas entre os mesmos, distribuídos sobre o plano gráfico (SÁ, 1996, 1998 CAMARGO, 2000; COUTINHO; SALDANHA, 2005).

O poder associativo encontra-se, a princípio, na magnitude da associação que esses elementos centrais da representação estabelecem uns com os outros - o poder de colocabilidade léxica (GREEBAUM, 1970 apud BACELAR DO NASCIMENTO; MENDES; ANTUNES, 2006). A análise da coocorrência das palavras evocadas permite a visualização da organização da Representação Social a partir da força com que os elementos ligam-se uns aos outros. Assim, obtém-se uma representação gráfica que mostra a centralidade e a conectividade dos diversos elementos. Nessa técnica admite-se que dois itens serão mais próximos na representação quanto mais elevado for o número de indivíduos que aceitem os dois ao mesmo tempo (SÁ, 1996). Tomamos a liberdade de apropriação das dicotomias de Ferdinand de Saussure (BARTHES, 2006), considerando a forte analogia existente entre o estudo da linguagem e o das representações sociais, ambas entendidas como construção coletiva, devendo ser diferenciadas, respectivamente, da fala e do discurso, que se configuram como propriedades individuais.

O nível culminante do poder associativo, proposto pelos autores, diz respeito à polissemia dos conceitos centrais, geradora de conotações próprias a cada grupo social, aqui tratada como o poder de associação léxica. Utilizamos a Técnica de Agrupamento Clustering Technique - para a verificação da equivalência semântica entre as evocações, complementando a análise de coocorrência. É uma técnica exploratória de análise multivariada que permite agrupar sujeitos ou variáveis em grupos homogêneos ou compactos relativamente a uma ou mais características comuns, baseando-se em suas similaridades. Neste estudo as palavras evocadas foram agrupadas de modo que as similaridades semânticas fossem agrupadas com respeito a alguns critérios de seleção predeterminados (MAROCO, 2003). Como método de variância, escolhemos o método de Ward (1983) cujo objetivo é minimizar o quadrado da distância euclidiana às médias dos conglomerados/agrupamentos. 
O objetivo desse tipo de análise é maximizar as similaridades existentes dentro dos grupos de palavras evocadas e minimizá-las entre os diferentes grupos, determinando, assim, seu poder associativo. Entendemos que os elementos com maior saliência e poder associativo assumem a condição de centralidade da representação porque mantém com o objeto da representação uma relação necessária, não negociável. Ou seja, na visão do grupo considerado, esses elementos não podem ser dissociados do objeto, sob pena de este perder toda a significação - todo o poder simbólico.

\section{Representação Social de professor entre os Docentes do Ensino Superior}

\subsection{O poder da Saliência}

Para esse grupo de docentes, apenas ensino e conhecimento compõem o Núcleo Central (NC) da Representação Social acerca do professor, restringindo sua qualidade a aspectos cognitivos (Figura 1a). O que emerge das evocações dos docentes do Ensino Superior parece ser uma representação ligada ao discurso normativo da profissão de professor considerando que, por questões históricas ou conceituais, o que se entende por ensinar esteja longe de ser consensual ou estático (FRANCO, 2004).

Tradicionalmente, a cultura acadêmica tem sido associada a um enciclopedismo tradicionalista, baseado na crença de que ter cultura acadêmica é ter capacidade de manejar um sistema conceitual padronizado dentro dos marcos de uma disciplina. De fato, o que tem caracterizado e distinguindo o docente, ao longo do tempo, em diferentes contextos e de diferentes formas, é a ação de ensinar. Até muito recentemente, como herança da cultura europeia, cultuávamos no Brasil, principalmente no ensino superior, a figura do professor catedrático, como expoente máximo da posse de um saber e do consequente poder de distribuí-lo, professá-lo, ensiná-lo. Via de regra, reproduzindo os padrões sob os quais foi formado, repetindo o que foi aprendido da forma como foi aprendido.

É importante considerarmos, que o reconhecimento da função de ensinar é, historicamente, muito anterior à emergência de um grupo profissional estruturado em torno dessa função; o que só ocorre na modernidade, mais propriamente a partir do século XVIII. 


\begin{tabular}{|c|c|c|c|c|c|c|c|}
\hline \multicolumn{2}{|c|}{ (1a) } & \multicolumn{3}{|c|}{ Grande Força de Evocação } & \multicolumn{3}{|c|}{ Pequena Força de Evocação } \\
\hline \multirow{3}{*}{ 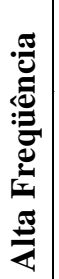 } & \multirow{3}{*}{$\begin{array}{l}0 \\
\text { 신 } \\
-1\end{array}$} & & & $\begin{array}{c}O M E \\
<4,3\end{array}$ & & f & $\begin{array}{l}O M E \\
\geq 4,3\end{array}$ \\
\hline & & Ensino & 26 & 2,69 & Atualização & 19 & 5,15 \\
\hline & & Conhecimento & 24 & 3,00 & & & \\
\hline \multirow{7}{*}{ 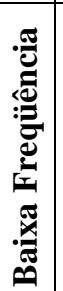 } & \multirow{7}{*}{$\begin{array}{l}\bullet \\
v \\
v\end{array}$} & Aluno & 14 & 3,21 & Prazer & 11 & 4,72 \\
\hline & & Pesquisa & 14 & 4,28 & Amizade & 8 & 5,00 \\
\hline & & Dedicação & 10 & 3,50 & Criatividade & 8 & 4,75 \\
\hline & & Educação & 10 & 2,50 & Persistência & 7 & 6,28 \\
\hline & & Orientador & 10 & 2,90 & Exemplo & 6 & 6,16 \\
\hline & & Relação & 5 & 3,40 & Diálogo & 5 & 6,40 \\
\hline & & Tédio & 5 & 3,20 & Zelo & 5 & 6,00 \\
\hline
\end{tabular}
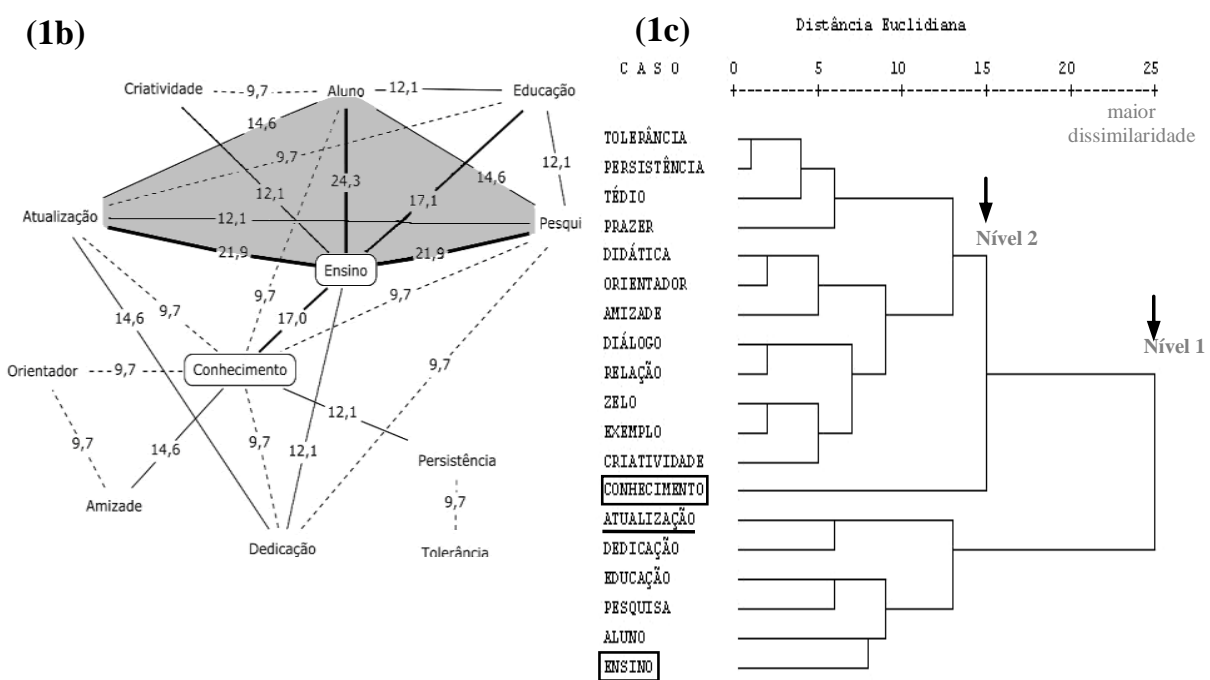

Figura 1 - Constituintes da Representação Social de PROFESSOR, entre os docentes do Ensino Superior do IBqM/UFRJ.

1a - Quadro de quatro casas - onde f é a frequiência simples de evocação; a média das frequiências (=16) estabelece a linha de corte entre Baixa e Alta Frequiência. OME é a Ordem Média de Evocação de cada palavra; a média das OME $(=4,30)$ estabelece a linha de corte entre Grande e Pequena Força de Evocação; a força está associada à prevalência na evocação, ou seja, a palavra citada na primeira posição tem força maior (valor $=1$ ) do que a citada na segunda posição (valor $=2$ ) e assim sucessivamente, desta forma, quanto menor o valor da OME, maior a força de evocação. ratamento dos dados: softare Evocation $2000^{\oplus}$ (Vergès, Scano e Junique, 2002).

1b - Gráfico de co-ocorrência - Foram selecionadas para essa análise palavras com freqüência mínima de cinco citações, evocadas por quatro (04) ou mais respondentes (quatro ou mais co-citações - representatividade mínima próxima de $10 \%$ entre os 41 respondentes). Foram consideradas as palavras citadas por quatro (04) ou mais respondentes (quatro ou mais co-citações); representatividade mínima de 9,7\% do total de respondentes. Percentuais de co-ocorrência, a saber:

$>\mathbf{2 0 \%} ; \quad>\mathbf{1 5 \%}$ e $\leq \mathbf{2 0 \%} ; \quad>\mathbf{1 0} \%$ e $\leq \mathbf{1 5 \%} ; \quad \leq \mathbf{1 0 \%}$. AIDECAT - software Evocation $2000^{\circledast}$ (Vergès, Scano \& Junique, 2002) e software $\mathrm{Cman} \mathrm{Tools}^{\circledR}$ (IHMC Florida).

$1 c$ - Dendograma dos elementos da Representação Social - os elementos dentro dos retângulos pertencem ao NC da representação e o elemento sublinhado pertence ao NPL, segundo as análises de saliência. Nível 1 e Nível 2 correspondem, respectivamente, ao primeiro e segundo níveis mais altos de dissimilaridade (baixa similaridade). 
A ideia de ensinar como a de professar o saber, para torná-lo acessível aos que não o possuíam, era socialmente justificável quando o saber era parco, pouco acessível e o seu domínio limitado a um número restrito de grupos ou indivíduos. Em um tempo de acesso amplo à informação e de estruturação das sociedades em torno do conhecimento, como capital global, o entendimento de ensinar como sinônimo de transmitir um saber deixou de ser socialmente útil e profissionalmente distintivo. Logo, nos parece que as representações centrais de professor, entre os docentes da Educação Superior, estão aprisionadas no século XIX. E, como toda modificação do Núcleo Central conduz a uma transformação completa da representação, descaracterizando o domínio identitário e ameaçando a estabilidade do grupo social, ensinar o conhecimento é, na representação desse grupo, a ideia mais resistente à mudança. Esse conjunto de reflexões sugere que a análise do sistema central nos permite descobrir o que há muito está estabelecido.

O sistema periférico parece ser mais rico e complexo do que o sistema central, por revelar a dimensão concreta da representação. Ou seja, a periferia da representação pressiona e contesta a realidade, atuando como um escudo do Núcleo Central” (ABRIC, 2003, p.31). Para esses docentes da Educação Superior, a palavra atualização aparece no Núcleo Periférico Limítrofe (NPL), portanto, com forte tendência a fazer parte do NC. (Figura 1a ). A questão da atualização está diretamente relacionada aos elementos que compõem o NC, por possuir, também, caráter cognitivo. Porém, a ligação mais contextual ocorreria com o conhecimento, que, por seu avanço e multiplicação, exige atualização constante. O Núcleo Periférico Intermediário (NPI), de baixa frequência e grande força de evocação, pode significar realidades particulares e contextos pessoais e, portanto, sem muita força no grupo. $\mathrm{O}$ que explica dedicação e tédio coexistirem no mesmo quadrante. Já os elementos de baixa frequência e pequena força de evocação, que constituem o Núcleo Periférico Externo (NPE), expressam as pressões impostas pela realidade ao grupo, com pouca aceitação entre os sujeitos que o compõe, no sentido de mudança das práticas e, consequentemente, de reformulação do NC (Figura 1a). Prazer, criatividade e persistência, assim como amizade, exemplo, diálogo e zelo, são aspectos que envolvem, respectivamente, a construção das competências afetivas e relacionais da profissão docente. Contudo, para os docentes da Educação Superior esses temas, por seu caráter de externalidade, representam apenas um discurso, mantendo intocado o Núcleo Central da Representação Social de professor - ensinar o conhecimento.

Encontramos em Capra (1999, p.37), uma explicação para "a centralidade da razão em nossa cultura" e, como conseqüência, para a marginalização da emoção na sala de aula. Deveríamos tratar a emoção como um aspecto tão importante quanto a própria inteligência e que, como ela, faz parte do ser humano, sendo fundamental para a compreensão da pessoa como um ser completo.

Segundo Piaget (1980, p.45), "não há comportamento afetivo sem vínculo cognitivo ou vice-versa, há apenas uma diferença de natureza". Neste sentido, a centralidade na quantificação e a excessiva visão unilateral da razão são limites impostos pela ciência moderna que necessitam ser ultrapassados, permitindo a construção de um novo paradigma 
para a apropriação do saber e, consequentemente, a constituição do ato educativo na contemporaneidade (Almeida, 1997, p.240).

Diversos estudos já demonstraram que a dimensão afetiva contribui para a aquisição de atitudes positivas em relação aos professores, às disciplinas por eles ministradas e, consequentemente, à aprendizagem dos alunos na sala de aula (ABREU, 2002). O interesse, como poderoso elemento da afetividade, influencia a seleção das atividades intelectuais, ou seja, a disposição para o aprendizado não é decorrente do sistema cognitivo, mas da afetividade. Nesse contexto, a boa convivência entre professor e aluno, afeição e espírito coletivo são fatores importantes e positivos para o sucesso na aprendizagem, também, na universidade. Em qualquer nível de ensino, o trabalho do professor consiste em tornar as vitórias possíveis (AITA; ARAÚJO, 2006).

Talvez, representações como as dos docentes universitários participantes desse trabalho expliquem porque, na prática dos professores e nos currículos dos cursos de formação, em diversas universidades brasileiras, as relações afetivas ainda não encontraram um lugar de equilíbrio no que concerne à dimensão cognitiva.

Recentemente, o pesquisador Jean Claude Abric (2003) realizou ampla revisão de estudos estruturais, concluindo que as práticas são dependentes das Representações Sociais, mas as representações dependem pouco das práticas. São vários os estudos experimentais, mostrando que os processos de transformação das Representações Sociais somente ocorrem quando os grupos são fortemente impelidos a adotar práticas (frequentemente, expressas na literatura como comportamentos ou atitudes) em contradição com elementos do sistema central da representação. No entanto, Abric (1993) esclarece que as dimensões quantitativas de frequência e força de evocação não são, por si só, determinantes do caráter inegociável dos elementos mais salientes; há, também, que considerar sua dimensão qualitativa, isto é, se esse elemento é ou não aquele que dá sentido à representação. Para isto, é necessário que, além da prevalência, o NC assuma, através da conectividade, o caráter da centralidade, em torno do qual se organizam os elementos periféricos.

\subsection{O Poder Associativo - da Colocabilidade Léxica}

A análise da colocabilidade léxica das evocações (coocorrências) parece confirmar a centralidade dos elementos ensino e conhecimento na representação social de professor, expressa pelos docentes do Ensino Superior (Figura 2), uma vez serem as evocações que estabelecem o maior número de associações com os demais elementos da representação (sete e oito ligações/arestas, respectivamente). Por outro lado, o baixo poder associativo do conhecimento apresentado na maioria das relações que constitui $(9,7 \%)$ indica a natureza frágil desse elemento na representação ou, mesmo, coloca em dúvida o seu pertencimento ao NC. A estrutura do gráfico de coocorrência sugere, também, que o elemento periférico limítrofe atualização está próximo de ser incorporado ao NC, tanto por se relacionar com os dois elementos do NC (conhecimento e ensino) quanto por formar, com eles, diversas estruturas geométricas, ligando-os entre si e a outros elementos da representação (Figura 2). O 
elemento atualização aparece vinculado mais fortemente $(21,9 \%)$ ao ensino, o qual estabelece os seus outros vínculos mais fortes com os elementos aluno e pesquisa (24,3\% e 21,9\%, respectivamente). Esta configuração tornaria atualização uma questão primordial nas representações desse grupo. Se não, vejamos. O NC ensinar o conhecimento representa a função histórica do professor, particularmente do catedrático universitário. Caso a atualização se configure como elemento da realidade que mais pressiona o NC, poderá vir a reformulá-lo, mas não a desestabilizá-lo, uma vez que é componente intrínseco da atividade principal exercida por esses sujeitos - a pesquisa. Em síntese, ensinar, para o aluno, o conhecimento atualizado relacionado à pesquisa que realiza pode se configurar como o código de ajustamento desse grupo ao ambiente educacional. 


\begin{tabular}{|c|c|c|c|c|c|c|c|}
\hline \multicolumn{2}{|c|}{ (2a) } & \multicolumn{3}{|c|}{ Grande Força de Evocação } & \multicolumn{3}{|c|}{ Pequena Força de Evocação } \\
\hline \multirow{3}{*}{ 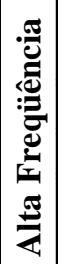 } & \multirow{3}{*}{$\begin{array}{l}n_{2}^{2} \\
\hat{\sigma}^{\prime}\end{array}$} & & $\mathbf{f}$ & $\begin{array}{c}O M E \\
<4,08 \\
\end{array}$ & & & $\begin{array}{l}O M E \\
\geq 4,08\end{array}$ \\
\hline & & Dedicação & 57 & 3,56 & Amor & 25 & 4,52 \\
\hline & & Tolerância & 50 & 3,94 & Compromisso & 22 & 4,22 \\
\hline \multirow{10}{*}{ 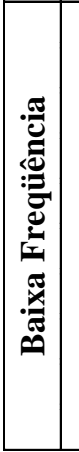 } & \multirow{10}{*}{$\begin{array}{l}n \\
\sigma^{2} \\
v\end{array}$} & Paciência & 9 & 3,66 & Conhecimento & 18 & 4,27 \\
\hline & & Vocação & 8 & 3,00 & Atualização & 17 & 5,35 \\
\hline & & Disciplina & 7 & 3,57 & Educação & 16 & 4,25 \\
\hline & & Educador & 6 & 1,50 & Superação & 13 & 5,76 \\
\hline & & & & & Ensino & 9 & 4,55 \\
\hline & & & & & Responsabilidade & 9 & 4,33 \\
\hline & & & & & Afeto & 8 & 5,50 \\
\hline & & & & & Relação & 8 & 5,25 \\
\hline & & & & & Esperança & 8 & 4,12 \\
\hline & & & & & Criatividade & 7 & 6,14 \\
\hline
\end{tabular}

(2b)

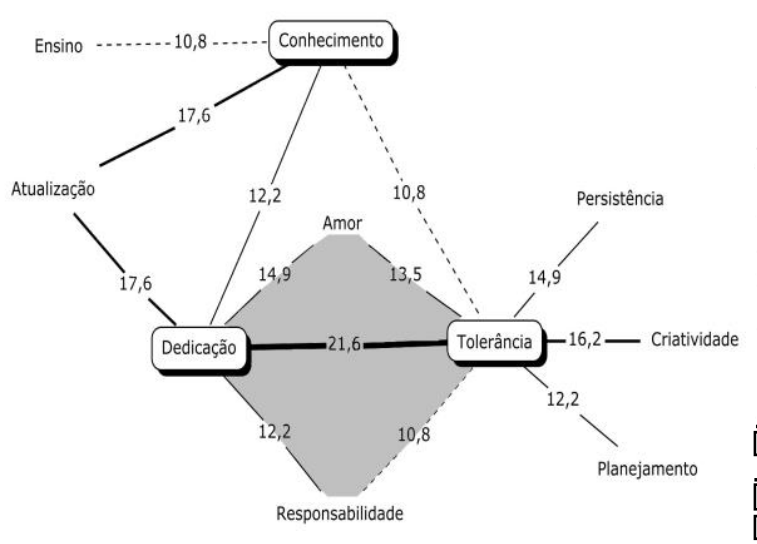

(2c)

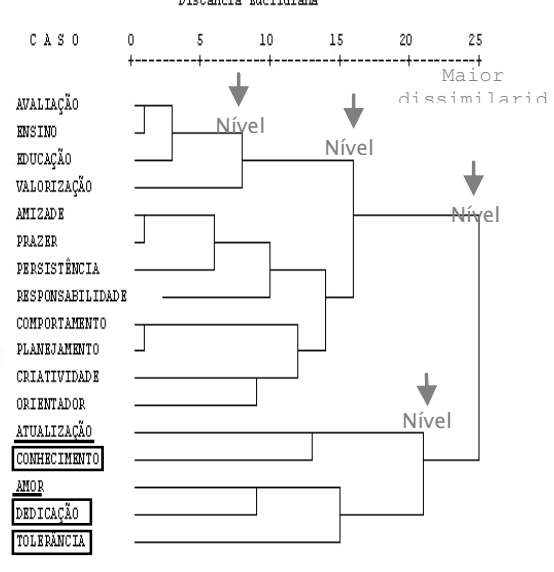

Figura 2 - Constituintes da Representação Social do PROFESSOR entre os docentes da Educação Básica, alunos do curso de Pós-Graduaão lato sensu do IBqM.

2a - Quadro de quatro casas com os elementos - onde f é a frequiência simples de evocação e Fmed é igual a 26. A média da Ordem Média de Evocações (OMEmed) é 4,30 em uma escala de 1 a 8 . As evocações com freqüência menor que 10 foram desprezadas. No quadro, força está associada à prevalência na evocação, onde a palavra citada na primeira posição tem força maior (igual a um) do que a citada na segunda posição (força igual a dois) e assim sucessivamente. Portanto, quanto menor o valor da OME maior a força de evocação.

2b - Gráfico de co-ocorrência - Foram consideradas as palavras citadas por quatro (04) ou mais respondentes ( $\overline{\text { oito }}$ ou mais co-citações); $\overline{\text { representatividade }}$ mínima de 10,8\% do total de respondentes. Diferentes percentuais de co-ocorrência: $\quad>\mathbf{2 0 \%} ; \quad>\mathbf{1 5 \%}$ e $\leq \mathbf{2 0 \%} ; \quad>\mathbf{1 0 \%} \mathrm{e} \leq \mathbf{1 5 \%} ; \quad \leq \mathbf{1 0 \%}$.

2c - Dendograma dos elementos da Representação Social - os elementos dentro dos retângulos pertencem ao NC da representação e o elemento sublinhado 
E este código de ajustamento estaria apoiado no fato da maioria dos docentes do IBqM ensinar em áreas muito próximas ou, pelo menos, afins às áreas em que pesquisam.

Entretanto, as demandas da sala de aula em que atuam extrapolam a oferta do conhecimento especializado. $\mathrm{O}$ esperado, nos primeiros anos do curso de graduação, de uma forma geral, é que os estudantes compreendam os princípios e estratégicas básicas de uma determinada área do conhecimento e as signifiquem nas relações que estabelecem com a prática profissional. O conhecimento atualizado em um campo específico da área não é suficiente para atingir esses objetivos. Esse descompasso entre o que se tem para ofertar e a demanda da realidade está longe de ser uma situação confortável; ao contrário, poderia ser causa de angústia. A possibilidade desses professores-pesquisadores se sentirem, no mínimo, desconfortáveis diante da docência, está enunciada na fragilidade da maioria das associações que o conhecimento estabelece com os demais elementos da representação (Figura 2). Outra faceta da representação de professor, evocada por esse grupo de docentes do Ensino Superior, se revela nos aspectos amizade, prazer, persistência e tolerância aparecem como elementos periféricos sem qualquer tipo de vínculo com os elementos aluno, ensino e educação, que podem ser considerados os componentes mais importantes da prática docente, visto que representam seu objeto e objetivo; seu motivo e finalidade.

Igualmente expressivo nessa configuração é o fato do ensino também não apresentar associação alguma com o elemento orientador, mesmo sendo esta a função que exercem diariamente nos laboratórios. Função indispensável à carreira de pesquisador, que, se levada para a sala de aula, daria ao ensino superior a perspectiva que dele se espera. Isto porque, a sala de aula deveria ser um espaço de estruturação conjunta de conhecimento. Um lugar de interações, diálogos, criações e trocas.

\subsection{O Poder da Associação Léxica}

A análise do dendograma, formado com todos os elementos da representação acerca de professor (Figura1c), mostra que o primeiro nível de agrupamento por dissimilaridade agrupa separadamente os elementos do NC - ensino e conhecimento, confirmando a ligação dos mesmos a dois contextos bem diferenciados. $\mathrm{O}$ ensino encontra-se agrupado aos aspectos concretos e cognitivos, expressos nos elementos atualização, educação, pesquisa e aluno (elemento mais similar). O conhecimento, apesar do seu isolamento semântico no segundo nível mais alto de dissimilaridade (discutido mais adiante), está circunscrito no grupo que vincula elementos de caráter relacional e afetivo, como tolerância, prazer, amizade, diálogo, zelo, criatividade, entre outros. Nesta análise, atualização, o elemento periférico limítrofe, forma com dedicação um agrupamento exclusivo, no menor nível de dissimilaridade, indicando possuírem significações similares na representação. Relendo esses resultados no sentido inverso ao divisório, podemos dizer que, para esses docentes do Ensino Superior, o grau de sinonímia entre atualização e dedicação é cerca de duas vezes maior do que entre atualização e os agrupamentos ensino/aluno - educação/pesquisa e quatro vezes maior do 
verificado entre atualização e conhecimento. Nesse caso, atualização perde seu caráter prático e provável - porque ligado à atividade de pesquisa - e assume a qualidade de desejo declarado, mas difícil de ser realizado - porque distante da pesquisa. Para esses docentes da Educação Superior, parece que a atualização exige dedicação, sem tempo e lugar no dia-a-dia profissional.

Como já mencionado, o conhecimento está isolado de todos os elementos da representação, o que sugere ser uma evocação cujo significado não tem par na representação de professor. Distante do ensinar, o conhecimento pode estar se transformando em um descritor sem pares conceituais, sem lugar no sistema de significações do ensino. Ensino entendido como uma relação que o professor desenvolve com o conhecimento sistematizado pela humanidade, no decorrer da sua história, visando a sua transmissão aos alunos. A perda do seu significado tradicional pode fazer com que o procedimento de ensinar deixe de ser deliberado e confortável, o bastante, para continuar imune aos aspectos relacionais e afetivos, próprios de uma nova prática docente que vem sendo imposta pela realidade. A sala de aula universitária, hoje, não pode mais ser entendida, meramente, como espaço físico de tempo determinado (poucas horas) onde o professor, senhor do saber, transmite conhecimentos aos alunos. "A sala de aula é todo espaço em que os alunos podem aprender" e essa aprendizagem precisa envolver o aluno como pessoa integrante de um contexto sociocultural, com sua história de vida, suas ideias, suas emoções, seus desejos, sua cultura, sua profissão (MASETTO, 2001, p. 87).

Essas contradições com as quais se deparam os professores do Ensino Superior inseridos no domínio profissional do IBqM/UFRJ parecem ter sua base na sobreposição dos aspectos próprios à atividade científica, que os identifica de fato, aos das questões docentes, estas de caráter eventual.

\section{A Representação Social de professor entre os Docentes da Educação Básica}

\subsection{O poder da Saliência}

Conhecimento, como observado para os docentes do Ensino Superior e os estudantes de Pós-Graduação, é um dos elementos do Núcleo Central das reapresentações sociais a respeito do professor. Mas, no NC desse grupo formado por docentes da Educação Básica, diferente dos antecedentes, o conhecimento vem precedido por tolerância e sucedido por dedicação, segundo a hierarquia de frequência e ordem média de evocações. Assim como verificado nas representações dos docentes do Ensino Superior, atualização aparece como elemento periférico limítrofe, aquele que estaria prestes a se inserir no NC.

As semelhanças entre os docentes do Ensino Superior e docentes da Educação Básica, cursistas da Pós-Graduação lato sensu, advindas da presença do conhecimento no NC e da 
atualização no NPL são suficientes para questionarmos se as representações desse grupo o distinguem do grupo social docentes da Educação Básica, nos levando a continuar a análise de suas representações e memórias como próprias de um grupo social específico. Para que esse grupo de docentes possua a qualidade de revelar as memórias e práticas profissionais do grupo social docentes da Educação Básica é imperativo que o NC da Representação Social desses docentes seja similar ao NC das representações de outros grupos de docentes, não frequentadores do IBqM (nem mesmo de forma esporádica) ou de qualquer outro curso de aperfeiçoamento ou especialização oferecido por universidades ou instituições de ensino superior. Professores que, como eles, lecionem nos quatro últimos anos do Ensino Fundamental e/ou nos três anos do Ensino Médio, em escolas das redes públicas dos diversos municípios da Região Metropolitana do Rio de Janeiro.

A análise das evocações acerca de professor entre 62 docentes da Educação Básica, que preenchiam as condições supracitadas, nos permitiu considerar que o quadro de Representações Sociais dos docentes da Educação Básica, internos ou externos ao IBqM, é limitado no exercício único da atividade docente - e por eles compartilhado. Portanto, trataremos os professores cursistas da pós-graduação lato sensu como um grupo portador legítimo das Representações Sociais dos docentes da Educação Básica acerca de professor, sob influência do ambiente acadêmico do Instituto.

Dessa forma, identificados entre si e díspares dos docentes do Ensino Superior, os professores da Educação Básica centralizam os sentimentos de dedicação e tolerância, na representação de professor conferindo-lhes estabilidade, proteção e caráter inegociável. Por outro lado, o elemento representacional conhecimento aparece com baixa frequência (30\%) e pequena força de evocação $(\mathrm{OME}=4,7)$ na representação dos docentes Externos ao IBqM, sugerindo ser uma questão central apenas para os docentes da Educação Básica cursistas da Especialização. Esse contexto de correspondências múltiplas pode ser interpretado já como indício de uma circunstância de inclusão desses docentes da Educação Básica no ambiente acadêmico-científico, ou, antes, como tendência de transposição de fronteiras entre duas instâncias educacionais - o Ensino Superior e a Educação Básica. Explorar a representação desse grupo de docentes da Educação Básica inseridos no IBqM, procurando a condição de centralidade dos elementos tolerância, conhecimento e dedicação, nos possibilita identificar o quão significativo é o contexto representado para o sujeito que o representa e, consequentemente, dimensionar o envolvimento desses docentes com a representação de professor.

\subsection{O Poder Associativo - da Colocabilidade Léxica}

Os elementos constituintes da representação de professor entre os docentes da Educação Básica foram analisados segundo suas coocorrências (Figura 2b). Tolerância não é apenas a evocação mais recorrente na representação de professor, como possui, também, o maior número de arestas, estabelecendo $53,8 \%$ de toda a coocorrência existente entre os elementos da representação. $\mathrm{O}$ elemento dedicação, evocado por um número representativo de sujeitos, porém menor $(37,8 \%)$, se insere em coocorrências que representam $38,4 \%$ da 
conectividade total da representação. O conhecimento aparece, aqui, relacionado mais fortemente à atualização, elemento do NPL. A estrutura do gráfico de coocorrência mostra, com clareza, o deslocamento do conhecimento em direção ao NPL e a ocupação do espaço central pelas evocações amor e responsabilidade. A fraca conectividade do conhecimento com os outros dois elementos do $\mathrm{NC}$, parece minimizar a força de sua centralidade. Esse conjunto de abordagens é um procedimento interessante e conveniente de investigação sobre as Representações Sociais que compõem as memórias dos sujeitos de diferentes grupos. A estrutura gráfica obtida da representação mostra que o que caracteriza o ser professor para os docentes da Educação Básica parece ser tolerância e dedicação.

\subsection{O Poder da Associação Léxica}

A força do elemento dedicação na Representação Social de professor surge com força entre os docentes da Educação Básica, sempre associada à tolerância e ao amor (Figura 2c). Esses três elementos afetivo-relacionais guardam significado com o conhecimento e atualização, no primeiro nível de dissimilaridade, quando se separam dos demais elementos da representação de professor. Agrupados por semelhança, conhecimento e atualização sucedem o agrupamento do NC, nos permitindo inferir que, na hierarquia das Representações Sociais, esses elementos ocupam, realmente, o núcleo periférico mais limítrofe ao NC. Portanto, o fato de frequentarem um instituto de pesquisa e cursarem uma Pós-Graduação lato sensu, na área de educação, não foi capaz de modificar o NC da Representação Social de professor, mas suas influências podem ser percebidas no núcleo limítrofe.

Os discursos e práticas que permeiam o ambiente do IBqM, talvez sejam os responsáveis por deslocar os elementos conhecimento e atualização, da condição de periferia externa da representação (como observado no grupo docente distante da academia), para a posição de periferia limítrofe, onde se alocam as questões com maiores chances de inclusão no NC. Os elementos valorização e prazer, planejamento e avaliação situados na periferia externa, são representações do ser professor que traduzem fundamentos de excelência da prática docente. Por isso, nos impressiona que sejam utilizados em discursos e eventuais práticas, apenas como forma de não expor o $\mathrm{NC}$, preservando o seu caráter intocado. Devemos considerar que as questões de valorização e avaliação, por estarem, a princípio, além das possibilidades individuais de solução, são bastante adequadas à função de blindagem do $\mathrm{NC}$, comprometendo, com isso, aspectos pessoais e profissionais imprescindíveis à prática docente de qualidade. Outro erro construído socialmente, de grandes e perigosas proporções pessoais e profissionais, é tratar como periféricas questões como afeto, criatividade, esperança, responsabilidade e superação ou, mais dramático, nem mesmo representá-las.

\section{Considerações Finais}

Por todos os questionamentos e reflexões suscitadas pela organização das RS, nem o ensinar conhecimento, nem a tolerância e nem a dedicação deveriam continuar sendo as 
evocações centrais das representações sociais de professor. Consequentemente, não deveriam mais distinguir os sujeitos, deixando de localizá-los em polos/grupos distintos de docente. Estaríamos compreendendo que essas diferenças posicionam os professores do Ensino Superior e da Educação Básica, em polos opostos e irreconhecíveis, acarretando as muitas barreiras de comunicação verificadas entre eles.

As observações resultantes do estudo de caso do IBqM nos impele à reflexão acerca das circunstâncias que implicam a manifestação de identidades docentes às vezes distintas, às vezes convergentes, entre os sujeitos pesquisados. Primeiro, é necessário se compreenda e aceite o caráter múltiplo e plástico da Identidade Docente. São diferentes faces de um único sujeito professor, que ora convivem, ora se alternam ou mesmo se rejeitam. Dimensões representacionais, discursivas e práticas que, muito além de serem consideradas complementares ou incompatíveis, devem ser entendidas como expressões de um sistema identitário complexo, constantemente pressionado a transitar por diferentes contextos. Discute-se, aqui, a implicação da identidade profissional assumida com circunstância institucional que impõe os tipos de relações e ações capazes de vencer os obstáculos enfrentados na prática. Em não havendo nas escolas, universidades e demais entidades educacionais uma tomada de posição pedagógica institucional, os caminhos da reformulação de práticas docentes ultrapassadas e da significação dos procedimentos educacionais serão, sempre, caminhos muito árduos de serem trilhados, muitas vezes por professores solitários. Sem uma opção consciente de um pensar e um fazer educacional, aceitos e postos em prática por todos os membros da instituição (de uma escola, uma faculdade, um instituto universitário), é mínima a possibilidade do professor, sozinho e individualmente, modificar sua prática e aprimorá-la continuamente, a fim de cumprir a função de assegurar o movimento contínuo do conhecimento produzido pelo homem, de geração em geração.

Cabe ao professor perpetuar a espécie social. Para isso ele trabalha cada indivíduo, fazendo com que se aproprie do conhecimento para, dessa forma, tornar-se socialmente mais apto. Indivíduos conhecedores e atuantes formam espécies sociais de sucesso.

Compreendendo a docência como uma prática profissional de grande complexidade e abrangência conceitual, cujos efeitos individuais e sociais são profundos e permanentes, obteremos resultados mais positivos no sentido de dinamizar o processo educacional.

\section{Referências}

ABREU, L. C. Mediação e Emoção. A Arte na Aprendizagem. In: CONGRESSO BRASILEIRO DE CIÊNCIAS DA COMUNICAÇÃO, 25, 2002, Salvador. Anais... Salvador: INTERCON/UNEB, 2002. p.326-329. 1 CD.

ABRIC, J. C. A abordagem estrutural das representações sociais. In: MOREIRA, A. S. P.; OLIVEIRA ,D. C. (Orgs). Estudos interdisciplinares de representação social. Goiânia: AB, 1998. p.87-88 
ABRIC, J. C. Abordagem estrutural das representações sociais: desenvolvimentos recentes. In: CAMPOS, P. H. F.; LOUREIRO, M. C. S. (Orgs.). Representações sociais e práticas educativas. Goiânia: Editora da UCG, 2003. p.37-57

AITA, G.; ARAÚJO, C. S. A. Afetividade e aprendizagem no ensino superior. Educere, v.6, n.1, p.49-60, Jan./Jun., 2006.

ALMEIDA, A. R. S. A emoção e o professor: um estudo à luz da teoria de Henri Wallon. Psicologia: Teoria e Pesquisa, Brasília, v.13, n.2, p.239-249, 1997.

BACELAR DO NASCIMENTO, M.F.; MENDES, A; ANTUNES, S. "Typologies of MultiWord Expressions Revisited: A Corpus-driven Approach", In: Y. Kawaguchi,.; S. Zaima; T. Takagaki, (Eds.). Spoken Language Corpus and Linguistic Informatics, Coll. Usage-Based Linguistic Informatics. Amsterdam/Philadelphia: John Benjamins Publishing Company, 2006. p. 227-244 (Vol.5).

BARTHES, R. Elementos de semiologia . 16 ed. Tradução de I. Blikstein. São Paulo: Cultrix, 2006.

CAMARGO, B. V. Sexualidade e representações sociais de estudantes universitários da UFSC sobre AIDS. Revista de Ciências Humanas, Santa Catarina, v.7, n.2, p.97-110, 2000.

CAPRA, F. O ponto de mutação. A ciência, a sociedade e cultura emergente. 20 ed. São Paulo: Cultrix, 1999.

CARBONE, R. A.; MENIN, M. S. S. Injustiça na escola: representações sociais de alunos do ensino fundamental e médio. Educação\& Pesquisa, São Paulo, v.30, n.2, p. 251-270, 2004.

COOLEY, C.H. Social organization: a study of the larger mind. New York: Schocken Books, 1962.

COUTINHO, M. P. L.; SALDANHA, A. A. W. (Eds.). Representações sociais e práticas em pesquisa. João Pessoa: Editora da Universidade Federal da Paraíba, 2005.

FLATH, E.; MOSCOVICI, S. Social representation. In: HARRÉ, R.; LAMB, R. (Orgs.). The dictionary of personality and social psychology. Londres: Blackwells, p. 123-124, 1983.

FRANCO, M. L. P. B. Representações sociais, ideologia e desenvolvimento da consciência. Cadernos de Pesquisa, São Paulo, v.34, n.121, p. 169-186, Jan/abr, 2004.

MAROCO, J. Análise estatística com utilização do SPSS. Lisboa: Edições, 2003.

MASETTO, M. T. Docência na Universidade. Campinas: Papirus, 2001. 
MOLINER, P. Cinq questions à propos des reprèsentations sociales. Cahiers Internationaux de Psychologie Sociale, França, v.16, n.20, p. 5-14, 1994.

MOSCOVICI, S. Representações Sociais: investigações em Psicologia Social. Petrópolis: Vozes, 2003.

PIAGET, J. A psicologia da criança. São Paulo/Rio de Janeiro: DIFEL, 1980.

SÁ, C. Sobre o núcleo central das representações sociais. Rio de Janeiro: Vozes, 1996.

SÁ, C. A construção do objeto de pesquisa em representações sociais. Rio de Janeiro: EdUERJ, 1998.

SHIMAMOTO, D. F; LIMA E. F. Representações sociais de professores de ciências sobre o corpo humano. Revista de Ciências Humanas, n. 39, p. 147-165, 2006

WARD, J. H. Hierarchical grouping to optimize an objective function. Journal of American Statistics Association, Texas, v. 58, n.301, p. 236-244. 1983.

Recebido em: março 2013

Aprovado para publicação em: outubro 2014 